\title{
Designing an Economic Valuation Model of the Intangible Assets of Volleyball Clubs in Iran
}

\author{
${ }^{1}$ Mohammad Ali Sahebkaran, ${ }^{1}$ Mahdi Talebpour ${ }^{*}$, ${ }^{1}$ Mohammad Keshtidar, \\ ${ }^{2}$ Mohammad Ghorbani \\ ${ }^{1}$ Department of Sport Management, Faculty of Sport Sciences, Ferdowsi University of Mashhad, \\ Mashhad, Iran. ${ }^{2}$ Department of Agricultural Economics, Ferdowsi University of Mashhad, Mashhad, \\ Iran.
}

Submitted 14 October 2018; Accepted in final form 14 December 2018.

\begin{abstract}
Background. Several studies have been conducted on the valuation of the intangible assets of organizations not relating to sport. However, there is no comprehensive study in the sport organizations especially in Iran. It is not clear what criteria are required at different levels by the sport organizations especially volleyball clubs to evaluate their intangible assets. Objectives. In spite of the increasing importance of the intangible assets in various industries, little has been done on the identification of the underlying factors and valuation of this category of assets in sport industry. Therefore, the purpose of this study was to design an economic valuation model of the intangible assets of the volleyball clubs in Iran. Methods. The sample of the present study in the qualitative section consisted of 47 subjects with 600 subjects participating in the quantitative section. Through application of Cochran formula, the sample size was estimated to be 234 subjects. The study was conducted in a survey method. To this end, first, the intangible assets of the Iranian volleyball clubs were identified using a qualitative method and then analyzed through structural equation modeling (SEM) $\mathrm{PLS}_{3}$ and $\mathrm{SPSS}_{22}$. Results. The factors with the greatest effects on economic valuation of intangible assets of Iranian volleyball clubs were communication capital, spiritual capital, structural capital and human capital. Thus, it was found that in the economic valuation of intangible assets of Iranian volleyball clubs, the indices such as the relationship between investors and partners and their loyalty in communication capital had the highest value among other indices. Further, the club history and success had the same status in promoting spiritual capital, governing culture of the club, development outlook document of the club in the structural capital, management of contracts, and the number of national players in the club in human capital. Conclusion. The results of the present study suggested that the proposed conceptual model can be applied by researchers, administrative and financial managers of volleyball clubs and the experts of the privatization organization to have a more comprehensive and precise evaluation of the valuation of intangible assets of a club.
\end{abstract}

KEY WORDS: Intangible Assets, Volleyball Clubs, Communication Capital, Spiritual Capital, Structural Capital, Human Capital.

\section{INTRODUCTION}

Sports clubs act as the pivotal component of the sports industry like an economic enterprise. Thorough benefiting from the equipment and facilities, skilled, expert and efficient work force, and effective management have turned themselves into an industry producing wealth

*. Corresponding Author:

Mahdi Talebpour, Associate Professor

Department of Sport Management, Faculty of Sport Sciences, Po.Box: 9177948979, Ferdowsi University of Mashhad, Azadi Sq.,

Mashhad, Iran.

E-mail: mtalebpour@um.ac.ir 
paving the ground for many developments in the world of sport (1). In other words, with increasing expansion of the sports industry, and the professional clubs at the lead, as well as the investments in sports all over the world, it is clear that continuous supervision over the various functions of these enterprises, especially in financial aspect is necessary to prepare them for rapid changes in the environment and use the resources, facilities and capacities of the clubs maximally. In this way, the clubs can achieve efficiency, effectiveness, and finally productivity (2). Further, as most of the economic activities are done in accordance with the conversion of existing wealth into current incomes and outcomes, estimation of the monetary value of services and assets in the sports industry can be highly constructive. Thus, one of the strategies which can support the economic capabilities of costly sport clubs is focusing on the marketing sector as well as economic approaches. The economic approach means enjoying "economic insight" and using economic instruments in accordance with the concepts and principles adopted by economics to solve problems and overcome hurdles. Examining the financial and economic trends of Iranian sports clubs suggests a major fundamental-economic problem. Nonetheless, reviewing the results of various studies indicate that ball sports such as football and volleyball have numerous potentials, assets, and values that which can be economic and income components, and then achieved through the process of economic valuation. The economic value is a magnitude expressed in terms of money which is payable in exchange for the acquisition of assets or rights arising from future interests using an asset. Hence, the economic value of each asset is its monetary value (3). In this regard, for the first time, Munasinghe (1993) divided the total economic value into two main branches - use and non-use values (4). Here, he also divided nonuse values into two groups: existential and legacy values where the use value includes direct, indirect, and selective use values. Thus, economic valuation is a process in which the current cost of an asset is determined. The most obvious form of asset is the tangible asset (market or use), such as buildings and office equipment and supplies, which are assets with a physical form and nature. Assets may be as intangible assets. Such assets in an economic unit include all assets with no physical nature but with significant benefits for the success of the economic entity (5). Intangible assets (non-market and non-use) of organizations (capability created by competency and knowledge sources) involve corporate structure, employees' specialized skills, innovation capability, customer size, brand, recognition, and market share demonstrating the opportunities for future growth and profitability of organizations. Many studies like Edvinsson (1993) have been conducted regarding economic valuation models, dividing market value into two parts - the book value and intangible assets (human capital and structural capital) (6). Brooking (1996) divided the intangible assets of an organization into four parts: human capital and sub-structural capital, intellectual property, and market capitals. Human-based assets are the skills, capabilities, expertise, chart-solving capabilities, and leadership styles. Sub-structural assets refer to all technologies, processes, and methodologies enabling an organization, and intellectual property is the franchise, brands of trade, and technical knowledge, signifying market capital, customers, loyalty of customers, and distribution channels (7). Roos et al. (1997) divided intangible assets into three parts: human capital, structural capital, and communicative capital. Human capital includes technical knowledge, skills, and leadership attributes of senior executives, innovations, motivation (financial and nonfinancial aspects) and compatibility. Structural capital is the corporate culture, structure, processes, and working procedures. Communicative assets refer to the customers, their satisfaction with products and services, number of customers, and communication with suppliers (being aware of these communications) (8). Bontis (2002) categorized the assets into four parts: human capital (learning and education, experience and expertise, creativity and innovation), structural capital (systems and programs, R \& D, intellectual property rights), communication capital (strategies and expectations, relationship with the customer, suppliers and the customer, and acquisition of knowledge about the customer). The last aspect in his division is intellectual asset or property (profitability, profitability, and value in the market) (9).

Chen et al. (2004) divided the assets of an organization into four parts (human capital, customer capital, innovation capital, and structural capital) (10). Jurczak (2008) classified 
the assets into human, organizational, and communicational capital. Human capital involves knowledge, competency, attitude, and mental issues; organizational capital is derived from intellectual, structural, commercial, market and developmental assets; and the communication capital includes customers, owners, investors, employees, distributors and manufacturers (11). Lopez (2009) considers the assets of an organization to have two main factors communiation capital (customer) and structural capital, two of which are objective knowledge and implicit knowledge (12). Chen (2012) categorized these assets into three types of structural capital, communicative capital, and human capital, whose value will vary with changes in the economic context (13). In a study entitled "The value of olympic achievements and the effects of the intangible assets of sport events in Germany", Wicker et al. (2012) showed that intangible assets by athletes create pride, national unity, satisfaction with prformance, national reputation, happiness, honor, and high performance in the society. They also contribute to enhancing motivation, promotion of justice, as well as willingness to pay for teams and sports clubs (14). Kapyla et al. (2012) as well as Salonius \& Lonnqvist (2012) divided the assets of an organization into four parts of human capital, spiritual capital, structural capital, and communicative capital $(15,16)$. In a study entitled "Measuring intangible assets of Turkish soccer clubs", Pinar Gurel et al. (2013) divided the intangible assets of the Turkish Premier League Clubs into three categories of human capital (individual skills such as talent, experience, knowledge, the merit of the employees and managers, motivation, knowledge and skills), structural capital (organizational structure, strategies, operational plans, information-transformation hardware and software and corporate culture), and communication capital or customer capital (club relationships with each other, relationships with sponsors and financial suppliers, relations with fans, and media relations) (17). Zhang et al. (2013) divided assets into three parts: human capital, spirituality, and commerce (18). In a study entitled "Personal well-being and intangible assets of the coaches of soccer clubs", Tomé et al. (2014) divided clubs assets into three categories of human capital or assets (the merit of club members as a source of productivity, quality, loyalty, individual skills and knowledge), structural capital (administrative infrastructure, databases, organizational knowledge, intellectual property), and communication capital (international relations of the club, image, relationships with external stakeholders, and the image of the club in the mass media). They also revealed that for evaluating a coach, the following points shouold be considered: the difference of the status of the team in the national league during the year, the status of the team in the competition table during the year, his image in the media, his personal history, being a former footballer, having sports activity in the team currently coaching, the championships won with the present team in previous years, the quality of the team's play, and the age of the individual. Additionally, the paper states that the most important factor affecting the price of coaches is nothing but their communication capital (19).

In a study entitled "Intellectual capital (intangible assets) and profitability in European football clubs", Dimitropoulos and Koumanakos (2015) concluded a positive and significant relationship between intangible assets and profitability of clubs. It should be noted that the intangible assets used in this study were organizational, human and communicative capital (20). In a study entitled "Intellectual capital and business performance in professional soccer societies: Evidence from a longitudinal analysis", Ricci et al. (2015) concluded that the intangible assets of sports clubs (structural / communications and human capital) are effectively and positively correlated with sport performance in clubs (21). Macerinskiene and Aleknaviciuterasa (2015) found a large overlap between the assets of organizations in different countries, where these dimensions differed among the studies in four and nine aspects, depending on the environment of different communities (22). Shou and Liu (2015) concluded that intangible sport assets, due to government constraints in the country, include acquisition of social credit for Chinese sports products companies from international sports events, brand naming rights, television broadcasting rights, respect for the society, and provision of sports products through the promotion of sports stars (23). Gudaityte et al. (2016) examined the criteria for assessing the sports event legacy (current share in the future) in the European Basketball Championship from 
2007 to 2013. They used the direct (infrastructure, sponsors, tourists, and return on investment) and indirect values (social and spiritual capital as well as communications) to value these events (24). In a study entitled "A framework for measuring intangible assets", Baldini et al. (2017) divided the assets of an organization into three types. One of them was communication capital (market share, the number of customers, sales returns, sales percentage, corporate image, customer trust, contracts, cooperation with other organizations, communication from the virtual spaces (human capital). The others were the human capital (the number of employees, staff age, employee experience, employee record, employee education, staff satisfaction, cooperation with specialist staff, employee motivation, employee training) and organizational capital (organizational growth index, patenting inventions, licensing, number of brands, employee perquisites, investing in the information systems, organizational innovation, and research costs) (25). Lardo et al. (2017) concluded that popularity criteria in social media are a determinant factor in the value of human and communication capitals in professional football clubs. The study divided the components of a club's assets into three parts: structural, human, and communication capitals (26). Bakhsha et al. (2018) concluded that the assets of an organization include three components: i) communication capital (brand value, relationship with suppliers and competitors, customer satisfaction, communication with other organizations, marketing capability, customer loyalty, and intensity of market competition); ii) structural capital (culture, organizational structure, organizational learning, access to new systems and information systems); and iii) human capital (employee experience, motivation, creativity, attitude and competence) (27). The results of the present study suggested that several studies have been conducted on the valuation of the intangible assets of organizations not relating to sport. However, there is no comprehensive study in the sport organizations especially in Iran. It is not clear what criteria are required at different levels by the sport organizations especially volleyball clubs to evaluate their intangible assets. Further, based on the governing situation in each country an efficient and domestic model has not been designed. On the other hand, the writers believe that the reason of unsuccessful or weak performance of the sport clubs in the past decades has been first the issues relating to the players, coaches and the facilities. Furthermore, other factors such as a nexus between sport (ministry of sport, sport federations, and sport organizations) and the sport industry, which is the correct valuation of sport clubs especially the intangible assets of volleyball clubs, and financial transparency between the investing group or the sport supporters and professional sport have been neglected despite their importance in the past decades. With regard to the abovementioned points, the researchers deal with the valuation of the intangible assets and the problems for transferring the sport clubs to the private section. In this regard, there have been various talks in private and public parts of academic and executive sections. The writers believe that developing a model for valuating the intangible assets of volleyball clubs can pave the way for the successful performance of the sport clubs in domestic and foreign tournaments. The economic valuation of intangible assets may be idealistic, yet developing an appropriate model makes it possible. Therefore, the present study intends to develop a model to valuate the intangible assets of Iranian volleyball clubs.

\section{MATERIALS AND METHODS}

Research Methodology. The information required to conduct the study was obtained using field studies, library, studies, questionnaires, and interviews. The study was conducted in two sections: qualitative and quantitative.

Participants and Procedure. The population in the qualitative part were faculty members of sport and economics management as well as managers of volleyball clubs in Iran (47 people). The sampling method in the qualitative section was snowball sampling. On the other hand, the population in the quantitative section was 600 people including faculty members of sport and economics management, athletes, coaches, managers and experts on economic valuation. In this study, stratified random sampling was used with the sample selected based on the Cochran formula by selecting 234 people (faculty members $=45$, coaches $=42$, athletes $=46$, managers $=13$ and experts $=88$ ). Initially, qualitative method was used to discover the intangible assets of Iranian volleyball clubs. In the qualitative section of this study, the researcher first examined the studies in this field after 
defining the research problem, after which some samples were selected purposively in the form of snowball sampling among faculty members of sport management and economics, athletes, coaches, managers and knowledgeable experts on the subject of economic valuation. The sampling continued up to information saturation (until the researcher did not find new information on the intangible assets of the Iranian volleyball clubs. Alternatively, when the indices proposed by the faculty members of sports management and economics, athletes, coaches, managers and experts were stated on the identical and repeated economic valuations). Overall, 35 individuals were interviewed in depth as face-to-face interviews (unstructured) and some notes were taken from the components of intangible assets of Iranian volleyball clubs stated in each dimension of communication capital, spiritual, human, and the structural capital. Note that the interviewer's position was cooperative during the interview.

Analysis and Processing Steps. The text of the interviews was analyzed by three quantitative, structural and interpretative methods. Structural method was used to classify the components in this study, where the researchers read the text of the interviews and terms several times, and identified the themes and phrases in the texts. Further, for greater validity, the research was not limited to interviews and previous studies were also used. Indeed, with the knowledge of the study of previous texts and other sources, the researcher tried to discover the meanings of words, sentences, and descriptive sentences. Finally, the economic valuation questionnaire for intangible assets of Iranian volleyball clubs was developed. Confirmatory factor analysis was utilized to confirm the validity of the structure of the questionnaire. According to the results, 76 indices were confirmed, where $34,15,19$, and 8 lied in the structural, spiritual, communication, and human dimensions, respectively. Note that all questions were based on the five-option Likert scale (one: very low value, two: low value, three: average value, four: valuable, and five: very valuable). The statistical method used in the quantitative part was the partial least squares (PLS), done in two steps. In the first step, the measurement model was examined through validation and reliability analysis along with confirmatory factor analysis (CFA). In the second step, the structural model was examined by estimating the path between the variables and determining the fit indices of the model (28).

Two types of logical and constructive validity were considered for evaluating the validity of the questionnaire. In this regard, content validity, face validity, and factor validity (factor analysis) were examined using SmartPLS software (Smart PLS3). According to Fornell and Larcker (1981), two criteria are used for factor analysis: i) factor loadings for observed variables should be greater than $0.05 ;$ i)) the reliability of all variables shows that the target factor is greater than 0.08. In a prudent approach, factor loadings larger than 0.7 have good validity (29).

Table 1. Results related to the validity and reliability of the research model in PLS software

\begin{tabular}{cccc}
\hline Variable & Cronbach's alpha & Combined reliability & AVE \\
\hline Human Capital & 0.832 & 0.837 & 0.446 \\
Communication capital & 0.930 & 0.939 & 0.528 \\
Spiritual capital & 0.870 & 0.895 & 0.505 \\
Structural capital & 0.899 & 0.915 & 0.512 \\
\hline
\end{tabular}

Fornell and Larcker (1981) approach was used to interpret factor loading values. The results indicated that 22 items related to the structural capital dimension, 4 to the dimension of spiritual capital, and 5 to the dimension of the communication capital were less than 0.4. So, these items did not have proper validity. However, the factor loading for other items was greater than 0.4 , showing good validity. On the other hand, the table data show that the combined reliability for all variables is greater than 0.8 and the average of the variance for all variables except one is greater than 0.50, demonstrating the high convergence validity. Considering the inappropriateness of the validity of 31 items in the questionnaire, the mentioned items were excluded from the analysis of the final model. Descriptive statistics were used to summarize and categorize raw data and calculate the mean, frequency, standard deviation, and plotting of charts and tables. At the level of inferential 
statistics, structural equation modeling was employed in partial least squares method to test the determinants and model fitness. SPSS22 and Smart PLS3 were used to test the hypotheses and model for analyzing the data. Then, in Figure 1, experts and researchers divided intangible assets of Iranian volleyball clubs into four dimensions of communication, human, spiritual, and structural capital.
Accordingly, using the structural method, the researchers identified the terms, words, and the existing text and themes after reading the text of the interviews several times. Further, they categorized and confirmed the aspects of economic valuation of the intangible assets of Iranian volleyball clubs by examining previous studies and views of the professors of sports management and economics.

\section{R: Communication capital}

r10: loyalty of fans, r11: the popularity of the club, r12: club brand identity, r13: brand awareness of the club, r14: perceived quality of the club by fans, r15: relationship of the club with fans, r16: social image of the club, r17: relationship with investors and partners, r18: club identity, r19: advertisement, r2: good fame (player and technical staff), r4: competitive advantage r7: Fans' satisfaction with medalists and current status of club, and r9: dealing with fans' criticisms.

\section{E: Human capital}

e1: number of fans, e2: talent scout by clubs (meritocracy), e3: contract management e4: human resources training and improvement (managers, coaches, players, etc.), e5: club pioneers, e6: number of national team players in the club, e7 club: reputation of human resources at both national and international levels (skills and individual values), and e8: the level of education of technical staff

\section{M: spiritual capital}

$\mathrm{m} 1$ : broadcasting rights (television, radio, satellite, etc.), m10: club successes, m2: membership of the club's representatives (coaches, players) in relevant international organizations (FIVB, AVC, etc.), m4: licenses and permits, M5: club age, M6: the honors of the clubs, m7: ranking of the clubs (nationally and internationally) m8: club families, M9: social capital, m13: the right to participate in national and international events, and $\mathrm{m} 15$ : values of Stocks relative to rivals.

\section{S: Structural capital}

S15: quality of owners and stakeholders, s16: development document (perspective, mission, etc.), s18: the share to participate in the professional league, s19: corporate culture, s20: research and publications on future development of the club, s22 club: efficiency and productivity of the club, s23 club ownership: s25, having coherent and efficient assessment programs in the club, s26: the geographical location of the club, s31: leadership style of the club managers, s36: effective managing in club, s4: using software packages and electronic systems

Figure 1. Classification of intangible assets of Iranian volleyball clubs 


\section{RESULTS}

After creating the open codes, they were The results indicated that the average age of 234 participants was 33.44 years, with 40 having a bachelor's degree (17.1\%), 77 a master's degree (32.9\%), and 117 (50\%) Ph.D. Table 2 represents the results of testing the model regarding path coefficients along with t-statistic in the hypotheses related to the model paths.

Table 2. Path coefficient values and $t$ statistics of the hypotheses related to the paths of the research model

\begin{tabular}{c|c|cccc}
\hline \multicolumn{2}{c}{ Relationship } & \multicolumn{1}{c}{ Path coefficient } & t statistic & Result & \\
\hline Structural capital & $\rightarrow$ & Economic valuation of club assets & 0.825 & 26.229 & Confirmed \\
Human Capital & $\rightarrow$ & Economic valuation of club assets & 0.788 & 43.260 & Confirmed \\
Communication capital & $\rightarrow$ & Economic valuation of club assets & 0.881 & 54.191 & Confirmed \\
spiritual capital & $\rightarrow$ & Economic valuation of club assets & 0.875 & 66.753 & Confirmed \\
\hline
\end{tabular}

Several criteria are used for studying the fit of a structural model: the first and most fundamental criterion is $t$ statistic. Specifically, the most basic criterion for measuring the relationship between variables in the model (the structural part) is the significance value of $t$. If the value of these numbers is greater than 1.96, the correlation between the variables is verified and the hypotheses are confirmed at $95 \%$ confidence level. In addition, the significance value refers to the same issue, and if it is less than 0.05 , then the relationship between the variables is confirmed at a confidence level of 0.95 . However, note that the numbers only signal the correctness of the relationship and the magnitude of the relationship between the variables cannot be measured. For understanding the intensity of the relationship and compare it with other relationships (relationships in the model), we can use the standardized coefficient. Considering the interpretive pattern in structural equation modeling, and as t-value of a path is larger than 1.96 , one can state that the corresponding path is significant at $95 \%$ level, so all the hypotheses were confirmed.

In the PLS approach, the quality and fit of the model are measured using several indices. Positive numbers indicate the quality of the model in the CV-Redundancy and CV-Redundancy test. The coefficient of determination or $\mathrm{R} 2$ represents how independent variables affect the dependent variable, with $0.19,0.33$ and 0.67 considered as a criterion value for weak, moderate, and strong values (30). In addition, for evaluating the overall model, the goodness of fit (GOF) is used as proposed by Tenenhaus and Vinz (2005). This criterion is calculated as follows:

$$
\text { GOF }=\sqrt{\overline{\text { Communalties }} \overline{R^{2}}}
$$

The values of $0.01,0.25$ and 0.36 have been proposed as weak, moderate, and desirable values for goodness of fit in the general model, respectively (31). The values of these indices are reported in Table 3.

Table 3.The value of fit indices for the variables of the research model

\begin{tabular}{cccccc}
\hline Variable & CV-Red & CV-Com & R2 & Communality & GOF \\
\hline Communication capital & 0.403 & 0.463 & 0.775 & 0.528 & 0.639 \\
spiritual capital & 0.321 & 0.317 & 0.776 & 0.443 & 0.575 \\
Structural capital & 0.310 & 0.354 & 0.680 & 0.474 & 0.567 \\
Human capital & 0.264 & 0.293 & 0.621 & 0.446 & 0.538 \\
\hline
\end{tabular}

According to the information in Table 3, the values obtained for studying CV-Red and CV-Com are all positive. Further, the values of $\mathrm{R} 2$ lie within the medium to strong range while GOF values are in the strong range, showing the quality of the test model. Then, the image of the tested model and the path coefficient obtained for all the paths of the model are displayed in Figures 2 and 3. 


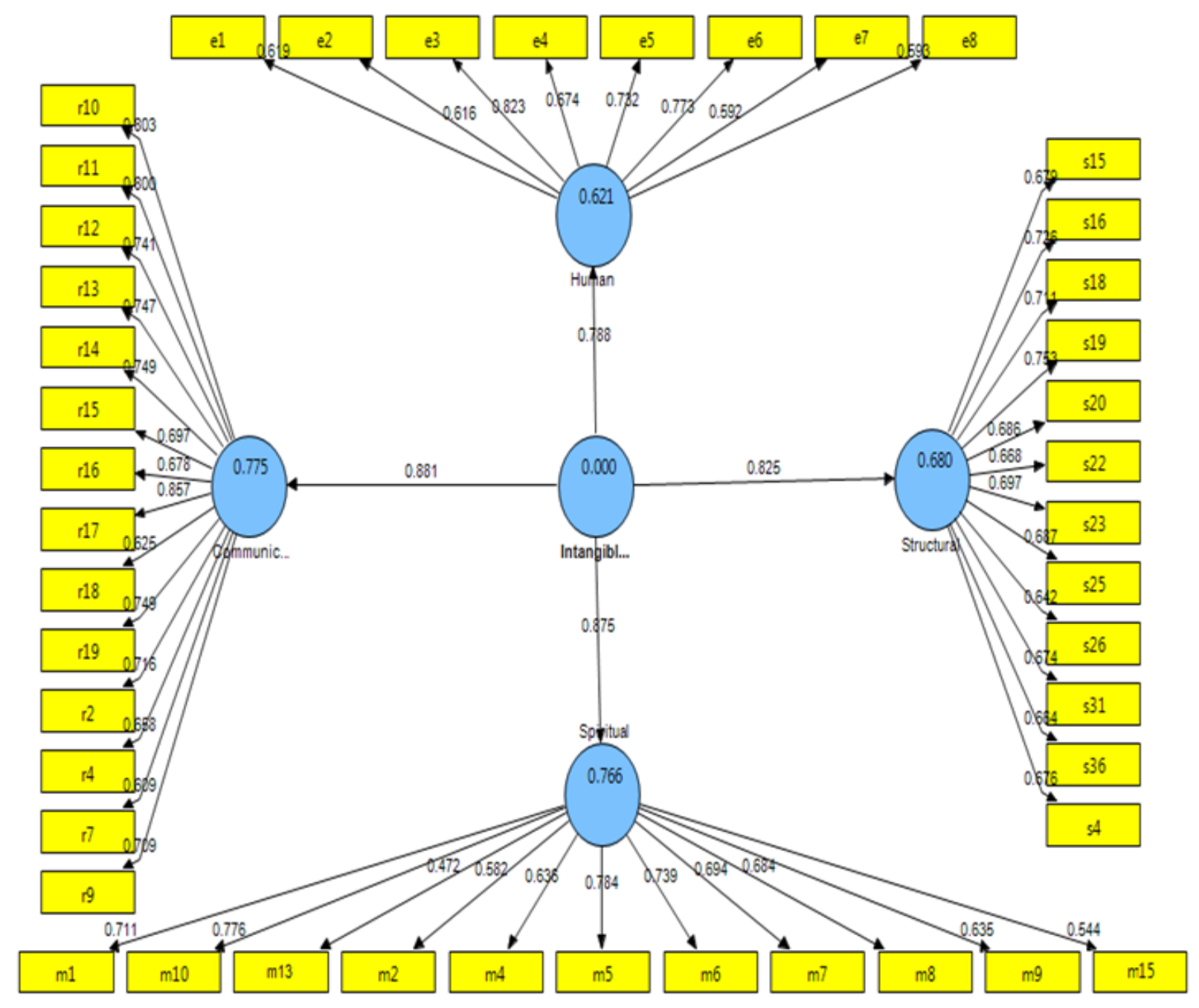

Figure 2. The final model of research in terms of path coefficient and factor loading.

- m1: Broadcasting rights (television, radio, satellite, etc.); m2: Membership of the club representatives in relevant international organizations (FIVB, AVC and so on); $\mathbf{m 4}$ : The right to participate in the tournaments; m5: Club age; m6: Awards gained by the club; m7: Club Ranking (national and international); m8: Club fame; m9: Social capital; m10: Club success; m13: Permits and licenses; m15: Stock value compared to competitors;

- r2: Recognition (player and technical staff); r4: Competitive Advantage; r7: Fans' satisfaction with medals and club stand; r9: Dealing with Criticism of team supporters; r10: Fan loyalty; r11: Club popularity; r12: Brand personality of the club; r13: Knowledge of club brand; r14: Perceived quality of the club; r15: The association of the club brand by fans; r16: Social image of the club; r17: Communication with the investors and patterns; r18: The identity of a club; r19: Promotion;

- s4: Using software packages and electronic systems; s15: Quality of Owners and shareholders; s16: Development document (vision, mission, etc.); s18: Presence in the Professional League; s19: Organizational Culture; s20: Publications and Research; s22: Efficiency and productivity of the club; s23: Club proprietary rights; s25: Having a coherent assessment program; s26: Geographical location; s31: Leadership style of the managers; s36: Effective management;

- e1: Number of fans; e2: Talent scout in the volleyball by the club; e3: Managing the contracts; e4: Improvement and training of human resources (managers, coaches, players, etc.); e5: Club pioneers; e6: The number of national players in the club; e7: The reputation of human resources at the national and international levels; e8: Educational level of the technical team. 


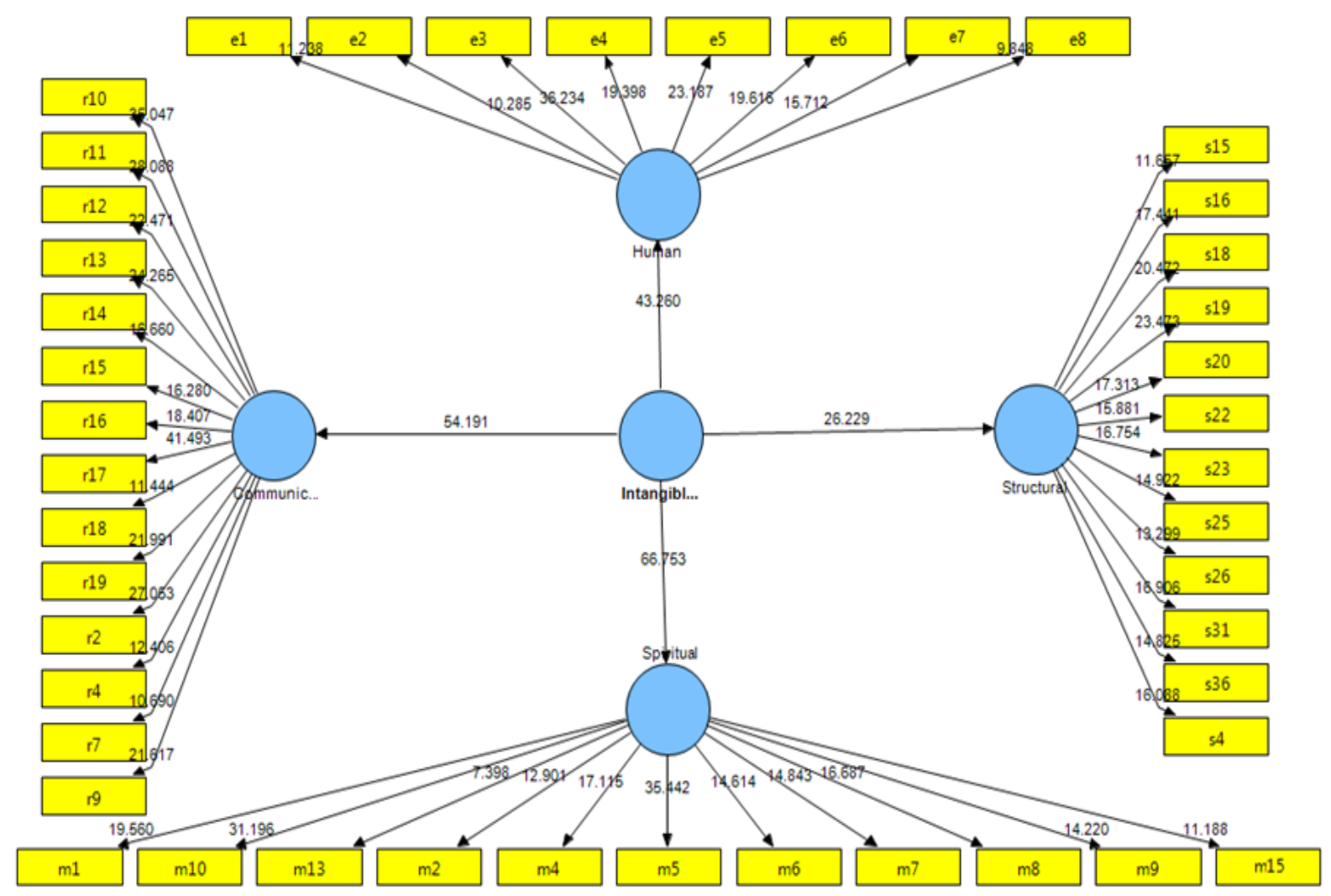

Figure 3. The final model of the research in the form of t values.m1: Broadcasting rights (television, radio, satellite, etc.); m2: Membership of the club representatives in relevant international organizations (FIVB, AVC and so on); m4: The right to participate in the tournaments; m5: Club age; m6: Awards gained by the club; m7: Club Ranking (national and international); m8: Club fame; m9: Social capital; m10: Club success; m13: Permits and licenses; m15: Stock value compared to competitors; r2: Recognition (player and technical staff); r4: Competitive Advantage; r7: Fans' satisfaction with medals and club stand; r9: Dealing with Criticism of team supporters; r10: Fan loyalty; r11: Club popularity; r12: Brand personality of the club; r13: Knowledge of club brand; r14: Perceived quality of the club; r15: The association of the club brand by fans; r16: Social image of the club; r17: Communication with the investors and patterns; r18: The identity of a club; r19: Promotion; s4: Using software packages and electronic systems; s15: Quality of Owners and shareholders; s16: Development document (vision, mission, etc.); s18: Presence in the Professional League; s19: Organizational Culture; s20: Publications and Research; s22: Efficiency and productivity of the club; s23: Club proprietary rights; s25: Having a coherent assessment program; s26: Geographical location; s31: Leadership style of the managers; s36: Effective management; e1: Number of fans; e2: Talent scout in the volleyball by the club; e3: Managing the contracts; e4: Improvement and training of human resources (managers, coaches, players, etc.); e5: Club pioneers; e6: The number of national players in the club; e7: The reputation of human resources at the national and international levels; e8: Educational level of the technical team.

\section{DISCUSSION}

The purpose of this study was to design a model for economic valuation of intangible assets of Iranian volleyball clubs. Descriptive analysis of the respondents' demographic characteristics revealed that more than $80 \%$ of the participants in the study had a postgraduate degree suggesting that the participants in this study had the required knowledge about economic valuation of the assets of the Iranian volleyball clubs. Regarding the age status of individuals, the results showed that most people $(40 \%)$ were within the age range of 30 and 40 , showing a combination of youth and experience as well as the suitable age of the individuals. The study demonstrated that the components of the capital investment have the greatest effect on the 
economic valuation of the intangible assets of Iranian volleyball clubs (path coefficient $=0.881$ ). According to the results, factor loadings of the indices of the communication capital of the volleyball clubs in Iran, included communication with the investors and partners (0.857), loyalty of supporters ( 0.803$)$, club popularity ( 0.800$)$, quality of the club by perceived by the fans and promotion (0.749), club brand awareness (0.747), and club brand identity (0.741), respectively. The others were reputation (player and technical staff) (0.716), dealing with fans' criticisms (0.708), association of club brand by fans (0.796), social image of the club (0.678), competitive advantage (0.658), club identity (0.625), and satisfaction of supporters with the medals, where the current position of the club with the highest gain of 0.609 had the highest factor loadings according to the respondents. The results were consistent with the results of pinar Gurel, Dagli Ekmekci, and Küçükkaplan (2013) regarding the components and indices (club relations with each other, relations with sponsors and financial suppliers, relations with fans, and media relations) identified (17). Communication capital seems to be considered as the key area of the club's intangible assets with stakeholders. It is possibly related to focusing on the attention of club managers to the inter-organizational issues of the clubs including the player, coach, and authorities. Thus, having strategic and operational plans can enhance the relationship between the internal and external factors of the clubs where the evaluation studies of the impact of each extra-organizational factor of intangible assets can be considered as effective.

The researchers concluded that the second most influential factor in the economic valuation of intangible assets of Iranian volleyball clubs is spiritual capital (path coefficient $=0.875$ ). According to the results, the factor loadings of the spiritual capital of Iranian volleyball clubs were as follows: the club's age (0.784), the club's successes (0.776), the club's honors (0.739), broadcasting rights (television, radio, satellite, etc.) (0.711), club ranking (national and international) (0.694). Further, club reputation (0.684), the right to participate in national and international competitions and events (0.636), social capital (0.635), membership in related international organizations (FIVB, AVC, etc.) 0.582 , stock value relative to competitors $(0.544)$, and licenses and permits (0.472) were the most significant ones according to the respondents. The results were consistent with the results of Mačerinskienè and Aleknavičiūte (2015) regarding the components and indices (the right to broadcast television, the right to participate in national and international competitions and events, club brand rights, advertising) identified (22). Productivity, profitability, and value in the club's indoor and outdoor environment as well as its environmental effects will lead to competitive advantage over other clubs. Estimating the weight of each factor of spiritual capital compared with other factors can be considered in augmenting the value and production of the club's wealth.

The results indicated that structural capital component is the third most important component of economic valuation of intangible assets of Iranian volleyball clubs (path coefficient $=0.825$ ). Based on the results, the factor loadings of the structural capital indices of the Iranian volleyball clubs included corporate culture (0.775), development document (outlook, mission, and so on) (0.726), the participation right in the professional league (0.711), club ownership rights (0.697), and having coherent and efficient evaluation programs in the club with (0.687) in the order of factor loadings. Also, research and publications on the development of plans of the club (0.686), the quality of owners and shareholders (0.679), using software packages and electronic systems (0.676), leadership style of club managers (0.674), efficiency and productivity in the club (0.668), effective management (0.664), and geographic location (0.642) had the highest factor loadings according to the respondents. The results here were in line with the studies by pinar Gurel, Dagli Ekmekci, and Küçükkaplan (2013) and Bakhsha, Afrazeh, and Esfahanipour (2018) regarding components and indices (organizational structure, strategies, operational plans, informationtransformation hardware and software, and corporate culture) identified (17, 27). Thus, attention to the development of infrastructure, i.e., strengthening organizational inputs of the club can lead to the club's success and reinforce the internal and external factors in intangible assets. Factors including organizational structure as well as soft and hard support, coupled with knowledge management and the agility of the club provide operational strategies for entering the processes. The great focus on the underlying factors and their effect on processes and their role in the intangible assets of the club need further consideration. 
Further, the researchers concluded that human capital is the fourth most influential factor in the economic valuation of intangible assets in Iranian volleyball clubs (path coefficient $=0.788$ ). According to the results, the factor loadings of the human capital indices of the Iranian volleyball clubs included the management of contracts $(0.823)$, the number of national players in the club (0.773), the club's pioneers (0.732), and the improvement and training of human resources (Managers, coaches, players, and so on) (0.674) in the order of factor loadings. The other ranks belonged to the number of fans (0.619), talent scout in volleyball clubs (meritocracy) (0.616), the level of education of technical staff (0.593), and the reputation of human resources at both national and international levels (personal skills and values), which showed the greatest significance or factor loadings according to the respondents. The results of this study were in line with Roos and Roos (1997) and Bakhsha, Afrazeh, and Esfahanipour (2018) in the components and indices (technical knowledge, skills, and leadership attributes of senior executives, innovations, motivation (financial and non-financial aspects) and compatibility, employee experience, attitude and competence) recognized $(8,27)$. Human capital is considered as the most important factor in the intangible assets of the club. Focusing on education, individual skills, experience and human capital merits as factors of education and training as the improvement and welfare of human capital can be considered as stimuli to increase the value of the club.

\section{CONCLUSION}

Overall, according to the results, one can claim that the criteria for valuation of intangible assets of Iranian volleyball clubs are factors including strategic goals and club reputation in structural capital, as well as leadership style of managers and using knowledge management in the club albeit with a relatively low weight. It seems that more precise studies can determine the accuracy of valuation in this regard by estimating each of the indices. As communication capital was one of the most important criteria in the valuation of intangible assets, and since factors such as relationship with investors and partners and their loyalty had a particular priority, they could be considered to have a higher relative weight in the economic valuation of the assets of Iranian volleyball clubs. On the other hand, the fans' satisfaction factors, the status of the club, and the identity of the club had a lower relative weight. Thus, the conditions of the other countries require further studies. Also, concerning the spiritual capital measure, factors such as stock values relative to other clubs and honors gained could have a higher relative weight, while membership in international organizations along with licenses and permits were among the last priorities in this study. In this regard, one may claim that the environmental conditions of the Iranian volleyball clubs could affect them where its impact can be examined in future studies. Finally, regarding the human capital in the economic valuation of intangible assets of the club, the contract management factors and the number of national players in the club had higher priorities, followed by financial transparency and talent scouting. Nevertheless, it seems that creating the necessary context for financial transparency, talent scouting, or meritocracy has not been considered well in Iranian volleyball clubs. Thus, more studies should be conducted in this regard.

In addition, the lack of enough financial resources in the previous years has turned into one of the most important problems faced by the government and the ministry of sport.

\section{APPLICABLE REMARKS}

- The Iranian volleyball federation obliges the professional leagues of volleyball clubs to evaluate their intangible assets by setting forth the related regulations.

- The research section of the volleyball league organization makes club managers familiar with the concepts of valuation and intangible assets by holding workshops.

- Some investigations are done on the improvement and development of the intangible assets.

- The proposed model be applied identification of the intangible assets of some unprofessional volleyball clubs and their results be compared with each other.

- The proposed model be applied in Rial valuation and price of each section be specified. Eventually, declare the real price for the private section. 


\section{REFERENCES}

1. Adams A, Armitage S. Mutuality for football clubs? Lessons from the financial sector. Studies in Economics and Finance. 2004;22(1):26-41. [DOI:10.1108/eb043381]

2. Asmild M, Paradi JC, Pastor JT. Centralized resource allocation BCC models. Omega. 2009;37(1):40-9. [DOI:10.1016/j.omega.2006.07.006]

3. Johnson BK, Whitehead JC. Value of public goods from sports stadiums: The CVM approach. Contemporary Economic Policy. 2000;18(1):48-58. [DOI:10.1111/j.1465-7287.2000.tb00005.x]

4. Munasinghe M. Environmental economics and sustainable development: The World Bank; 1993. [DOI:10.1596/08213-2352-0]

5. Damodaran A. Investment valuation: Tools and techniques for determining the value of any asset: John Wiley \& Sons; 2012.

6. Edvinsson L. Intellectual Capital: Realizing Your Company's True Value by Finding Its Hidden Brainpower: HarperCollins; 1997. 240 p. [PMCID]

7. Brooking A. Intellectual capital: core asset for the third millennium. 2nd ed. London: International Thomson Business Press; 1996. 204 p.

8. Roos G, Roos J. Measuring your company's intellectual performance. Long range planning. 1997;30(3):413-26. https://doi.org/10.1016/S0024-6301(97)90260-0 [DOI:10.1016/S0024-6301(97)00022-8]

9. Bontis N, Fitz-Enz J. Intellectual capital ROI: a causal map of human capital antecedents and consequents. Journal of Intellectual capital. 2002;3(3):223-47. [DOI:10.1108/14691930210435589]

10. Chen J, Zhu Z, Yuan Xie H. Measuring intellectual capital: a new model and empirical study. Journal of Intellectual capital. 2004;5(1):195-212. [DOI:10.1108/14691930410513003]

11. Jurczak J. Intellectual capital measurement methods. Economics and organization of enterprise. 2008;1(1):37-45. [DOI: 10.2478/v10061-008-0005-y]

12. Lopes IT, Rodrigues AMG. Intangible Assets Identification and Valuation--a Theoretical Framework Approach to the Portuguese Airlines Companies. Electronic Journal of Knowledge Management. 2007;5(2).

13. Chen L. A mixed methods study investigating intangibles in the banking sector: University of Glasgow; 2012.

14. Wicker P, Hallmann K, Breuer C, Feiler S. The value of Olympic success and the intangible effects of sport eventsa contingent valuation approach in Germany. European sport management quarterly. 2012;12(4):337-55. [DOI:10.1080/16184742.2012.693117]

15. Käpylä J, Kujansivu P, Lönnqvist A. National intellectual capital performance: a strategic approach. Journal of Intellectual Capital. 2012;13(3):343-62. [DOI:10.1108/14691931211248909]

16. Salonius H, Lönnqvist A. Exploring the policy relevance of national intellectual capital information. Journal of Intellectual Capital. 2012;13(3):331-42. [DOI:10.1108/14691931211248891]

17. pinar Gurel S, Dagli Ekmekci YA, Küçükkaplan İ. Measuring intellectual capital for football clubs: evidence from Turkish first division football league. Pamukkale Journal of Sport Sciences. 2013;4(1):36-47.

18. Zhang X-p, Shang R-h, Zhang X-y, editors. Managing Intangible Assets of Sports Celebrities in China. Proceedings of 20th International Conference on Industrial Engineering and Engineering Management; 2013: Springer. [DOI:10.1007/978-3-642-40072-8_84]

19. Tomé E, Naidenova I, Oskolkova M. Personal welfare and intellectual capital: the case of football coaches. Journal of Intellectual Capital. 2014;15(1):189-202. [DOI:10.1108/JIC-06-2013-0064]

20. Dimitropoulos PE, Koumanakos E. Intellectual capital and profitability in European football clubs. International Journal of Accounting, Auditing and Performance Evaluation. 2015;11(2):202-20. [DOI:10.1504/IJAAPE.2015.068862]

21. Ricci F, Scafarto V, Celenza D, Gilvari IS. Intellectual Capital and Business Performance in Professional Football Clubs: Evidence From a Longitudinal Analysis. Journal of Modern Accounting and Auditing. 2015;11(9):450-65.

22. Mačerinskienė I, Aleknavičiūtė R. Comparative evaluation of national intellectual capital measurement models. Business: Theory and Practice. 2015;16(1):1-14. [DOI:10.3846/btp.2015.548]

23. Shou Z-q, Liu P. Development and Utilization of Sports Intangible Assets in China under Sustainable Development Perspective. Open Cybernetics \& Systemics Journal. 2015;9:3018-23. [DOI:10.2174/1874110X01509013018]

24. Gudaityte G, Jasinskas E, Balciunas M, Streimikiene D. Evaluation of the legacy of a sporting event: a case of EUROBASKET 2007-2013. Transformations in Business \& Economics. 2016;15(2).

25. Baldini MA, Bronzetti G, Sicoli G. A Framework to Measure Intellectual Capital. Country Experiences in Economic Development, Management and Entrepreneurship: Springer; 2017. p. 527-37.

26. Lardo A, Dumay J, Trequattrini R, Russo G. Social media networks as drivers for intellectual capital disclosure: Evidence from professional football clubs. Journal of Intellectual Capital. 2017;18(1):63-80. [DOI:10.1108/JIC09-2016-0093] 
27. Bakhsha A, Afrazeh A, Esfahanipour A. Identifying the Variables of Intellectual Capital and Its Dimensions with the Approach of Structural Equations in the Educational Technology of Iran. EURASIA Journal of Mathematics, Science and Technology Education. 2018;14(5):1663-82. [DOI:10.29333/ejmste/85037]

28. Hulland J. Use of partial least squares (PLS) in strategic management research: A review of four recent studies. Strategic management journal. 1999;20(2):195-204. https://doi.org/10.1002/(SICI)10970266(199902)20:2<195::AID-SMJ13>3.0.CO;2-7 [DOI:10.1002/(SICI)1097-0266(199902)20:23.0.CO;2-7]

29. Fornell C, Larcker DF. Evaluating structural equation models with unobservable variables and measurement error. Journal of marketing research. 1981:39-50. https://doi.org/10.2307/3151312 [DOI:10.1177/002224378101800104]

30. Chin WW. The partial least squares approach to structural equation modeling. Modern methods for business research. 1998;295(2):295-336.

31. Tenenhaus M, Vinzi VE, Chatelin Y-M, Lauro C. PLS path modeling. Computational statistics \& data analysis. 2005;48(1):159-205. [DOI:10.1016/j.csda.2004.03.005] 